\title{
Pengambilan Sampel Air Sungai Gajah Wong di Wilayah Kota Yogyakarta
}

\author{
Rahmi Ahdiaty* dan Dewi Fitriana \\ UPT Laboratorium Dinas Lingkungan Hidup, Yogyakarta, Indonesia \\ *corresponding author : ahdiaty@gmail.com \\ DOI : 10.20885/ijca.vol3.iss2 .art4
}

\begin{tabular}{|c|c|}
\hline ARTIKEL INFO & ABSTRAK \\
\hline $\begin{array}{l}\text { Diterima : } 19 \text { Juni } 2020 \\
\text { Direvisi } \quad \text { : } 20 \text { Juli } 2020 \\
\text { Diterbitkan : 09 September } 2020 \\
\text { Kata kunci : Sungai Gajah Wong, } \\
\text { pengambilan sampel, debit, } \\
\text { insitu, pengawetan sampel }\end{array}$ & $\begin{array}{l}\text { Sungai Gajah Wong, salah satu sungai di Kota Yogyakarta dimana } \\
\text { penggunaan air sungai Gajah wong untuk keperluan sehari-hari } \\
\text { masih sangat banyak ditemui di bantaran sungai ini, dikhawatirkan } \\
\text { terpapar pencemaran air akibat pembuangan limbah rumah tangga, } \\
\text { industri, rumah sakit maupun hotel yang masuk ke dalam } \\
\text { alirannya. Hal ini menyebabkan penurunan kualitas air sungai dan } \\
\text { menimbulkan dampak negatif bagi makhluk hidup yang } \\
\text { memanfaatkannya. Pemantauan DAS (Daerah Aliran Sungai) } \\
\text { sangat penting dilakukan karena berkaitan dengan air atau sungai } \\
\text { sebagai sumber kehidupan bagi makhluk hidup. Salah satu cara } \\
\text { untuk pemantauan DAS yaitu dengan cara melakukan } \\
\text { pengambilan sampel air sungai pada } 5 \text { (titik) sungai Gajah Wong } \\
\text { yang ada di wilayah Kota Yogyakarta. Pengambilan sampel air } \\
\text { dilakukan untuk mengetahui kualitas air sungai dengan meliputi } \\
\text { pengukuran debit air, pengujian parameter insitu (pH, TDS, daya } \\
\text { hantar listrik, suhu dan Dissolved Oxygen) dan perlakuan } \\
\text { pengawetan sampel untuk parameter yang diuji di laboratorium. } \\
\text { Hasil pengukuran untuk paremeter insitu pH dan DO pada GW } 1 \\
\text { ada di bawah baku mutu yang dipersyaratkan. Sedangkan } \\
\text { parameter suhu, DHL dan TDS masih memenuhi baku mutu yang } \\
\text { dipersyaratkan. }\end{array}$ \\
\hline
\end{tabular}

\begin{tabular}{ll}
\hline ARTICLE INFO & ABSTRACT \\
\hline Received : 19 June 2020 & Gajah Wong River, one of the rivers in the city of Yogyakarta \\
Revised : 30 July 2020 & where the use of Gajah Wong river water for daily use is still very \\
Published : O9 September 2020 & much found on the banks of this river, it is feared to be exposed to \\
Keywords : Gajah Wong River, & water pollution due to disposal of household waste, industry, \\
sampling, river flow, in situ, & hospitals and hotels that enter into the flow. This causes a decrease \\
sample preservation & in the quality of river water and has a negative impact on living \\
& things that make use of it. Watershed monitoring is very important \\
& because it is related to water or rivers as a source of life for living \\
& things. One way to monitor watersheds is by taking river water \\
& samples at 5 (points) of the Gajah Wong river in the Yogyakarta \\
& City. Sampling is carried out to determine the quality of river \\
& water by including measurement of water discharge, testing in situ \\
& parameters (pH, TDS, electrical conductivity, temperature and \\
& Dissolved Oxygen) and preserving treatment of samples for \\
& parameters tested in the laboratory. The measurement results for \\
& parameters in situ pH and DO in GW 1 are below the required \\
& quality standards. While the temperature parameters, DHL and \\
& TDS still have good agreement with the required quality \\
& standards.
\end{tabular}




\section{PENDAHULUAN}

Sungai Gajah Wong yang merupakan sub DAS Opak, dan memiliki luas 46,082 $\mathrm{km}^{2}$. Secara administrasi terletak di Kab. Sleman di bagian hulu,meliputi Kecamatan Pakem, Ngemplak, Ngaglik,dan Depok. Untuk bagian tengah DAS termasuk ke dalam wilayah Kota Yogyakarta, meliputi: Kecamatan Umbulharjo, Kotagede, Gondokusuman, sedangkan di bagian hilir DAS termasuk wilayah Kabupaten Bantul, meliputi: Kecamatan Pleret dan Banguntapan [1]. Sungai Gajah Wong merupakan salah satu sungai di Yogyakarta yang mengalami dampak pencemaran akibat semakin banyaknya bahan buangan dari limbah rumah tangga, industri, rumah sakit maupun hotel [2]. Penggunaan air yang tidak memenuhi kriteria standar kualitas sesuai peruntukannya dapat menimbulkan gangguan terhadap kesehatan yang diakibatkan oleh keberadaan mikroorganisme patogen, zat kimia beracun dan zat radioaktif [3]. Indikator pencemaran sungai tersebut dapat diamati secara fisik, kimiawi, mikrobiologis, radioaktivitas serta senyawa organik dan pestisida [4]. Daerah Aliran Gajahwong sebagian besar dimanfaatkan untuk berbagai kegiatan domestik, industri, dan pertanian. Limbah dari kegiatan kegiatan tersebut yang umumnya langsung dibuang ke dalam sungai dan akan berdampak sangat buruk terhadap kualitas air sungai-sungai tersebut. Dampak buruk terhadap kualitas air sungai tergantung dari jenis, jumlah dan sifat dari limbah yang masuk ke dalam sungai [5].

Lokasi pengambilan sampel ditentukan berdasarkan pada tujuan pemeriksaan.

a). Untuk pengawasan pencemaran air sungai (perairan penerima) sampel diambil pada tiga titik yaitu:

- Pada titik perairan penerima sebelum tercampur limbah cair dari suatu kegiatan.

- Pada saluran pembuangan limbah cair (Outlet IPLC) sebelum dialirkan/masuk ke perairan penerima.

- Pada titik perairan penerima setelah tercampur dengan limbah cair dari kegiatan yang bersangkutan, namun belum tercampur limbah cair lainnya.

b). Untuk keperluan evaluasi effisiensi IPAL

Sampel diambil pada titik sebelum dan setelah IPLC dengan catatan memperhatikan waktu retens (waktu tinggal).

c). Untuk keperluan pemantauan air sungai, titik pengambilannya sbb :

- Pada air sungai di bagian hulu (sebelum masuk kota)

- Pada air sungai di bagian tengah (tengah kota)

- Pada air sungai di bagian hilir (setelah keluar kota)

Pengambilan air sungai Gajah Wong dilakukan sesuai dengan SNI No. 6989.57:2008 Air dan air limbah - bagian 57 : Metoda pengambilan sampel air permukaan, dan hasil pengujian dibandingkan dengan PerGub DIY No. 20 tahun 2008 tentang baku mutu air sungai.

Pemantauan air sungai Gajah Wong di wilayah Kota Yogyakarta, dilakukan pada 5 lokasi pengambilan sampel dengan meliputi pengukuran debit air, pengujian parameter insitu (pH, TDS, konduktivitas, suhu dan Dissolved Oxygen) dan perlakuan pengawetan sampel untuk parameter yang diuji di laboratorium.

\section{METODE PENELITIAN}

\subsection{Alat dan Bahan}

Aquades, botol sampel, pompa vacuum, GPS, ice box, DO meter, $\mathrm{pH}$ meter, thermometer, konduktimeter, current meter, reagen untuk pengawetan, ice gel.

\subsection{Penentuan Titik Pengambilan Sampel}

Pengambilan sampel di Sungai Gajah Wong ditentukan berdasarkan pada keperluan pemantauan air sungai yang mewakili hulu, yaitu aliran sungai yang masuk ke wilayah Kota Yogyakarta (Jembatan Santo Thomas), tengah kota (Jembatan Balirejo, Jembatan Gembiraloka dan Jembatan Logathok), dan hilir (Jembatan Tegalgendu). Saat pengambilan sampel, titik lokasi di catat dengan GPS 


\subsection{Pengambilan Sampel Air}

Pengambilan sampel pada penelitian ini dilakukan dengan metode pengambilan sampel uji gabungan tempat (Integrated place sample) yaitu campuran dari beberapa contoh yang diambil pada satu saluran dari beberapa titik tertentu dengan volume dan waktu yang sama yaitu sampel diambil secara horizontal (kiri, tengah, dan kanan) masing-masing sebanyak 1 liter, lalu dikomposit, displit, dan dilakukan pengawetan sampel untuk parameter yang dianalisis di laboratorium.

Titik pengambilan sampel air sungai ditentukan berdasarkan debit air sungai yang diatur dengan ketentuan sungai dengan debit kurang dari $5 \mathrm{~m}^{3} /$ detik, sampel air diambil pada satu titik ditengah sungai pada kedalaman 0,5 kali kedalaman dari permukaan sehingga diperoleh sampel air dari permukaan sampai ke dasar secara merata. Sungai dengan debit antara $5 \mathrm{~m}^{3} /$ detik $-150 \mathrm{~m}^{3} /$ detik, sampel air diambil pada dua titik masing-masing pada jarak $1 / 3$ dan $2 / 3$ lebar pada kedalaman 0,5 kali kedalaman dari permukaan sehingga diperoleh sampel air permukaan sampai ke dasar secara merata kemudian dicampurkan. Sungai dengan debit lebih dari $150 \mathrm{~m}^{3} /$ detik, sampel air diambil minimum pada enam titik masing-masing pada jarak $1 / 4,1 / 2$, dan $3 / 4$ lebar sungai pada kedalaman 0,2 dan 0,8 kali kedalaman dari permukaan sehingga diperoleh sampel air dari permukaan sampai ke dasar secara merata lalu dicampurkan [9].

Pengambilan sampel air dilakukan dengan tahapan yaitu alat pengambil sampel air dibilas dengan air yang akan diambil sebanyak tiga kali. Sampel air diambil sesuai dengan peruntukkan analisis, antara lain untuk logam, BOD, COD, dan parameter lain yang diperlakukan sesuai dengan tabel III. Pengujian untuk parameter suhu, TDS, daya hantar listrik, $\mathrm{pH}$, dan oksigen terlarut yang dapat berubah dengan cepat dan tidak dapat diawetkan dilakukan di lokasi tempat pengambilan sampel air yang kemudian hasil pengujian parameter lapangan dicatat dalam lembar lapangan maupun buku catatan khusus.

Sebagai jaminan mutu pengambilan sampel, maka dilakukan pengambilan sampel untuk sampel duplikat dan blanko media maupun blanko perjalanan. Sampel duplikat merupakan sampel yang diambil dari titik yang sama pada waktu yang hampir bersamaan dengan jumlah sampel minimal 5 titik lokasi. Blanko media yang diambil selama pengambilan sampel, digunakan untuk mendeteksi kontaminan pada media yang digunakan dalam pengambilan sampel merupakan wadah yang diambil secara acak dan diisi dengan media bebas analit untuk dibawa ke lokasi pengambilan sampel dan dibawa kembali ke laboratorium untuk diuji. Sedangkan blanko perjalanan digunakan jika sampel yang diambil bersifat mudah menguap, yang dibawa ke lokasi pengambilan dan ditutup selama pengambilan sampel kemudian dibawa kembali untuk diuji di laboratorium. Hasil blanko media maupun blanko perjalanan digunakan sebagai faktor koreksi pada perhitungan jika, [blank] $\leq$ MDL, maka tidak ada kontaminasi silang sehingga hasil pengujian blanko tidak digunakan sebagai faktor koreksi sedangkan jika, [blank] > LoQ, maka terjadi kontaminasi silang sehingga hasil pengujian sampel dikurangi dengan hasil pengujian blanko [9].

\subsection{Pengukuran Debit}

Penentuan tempat pengukuran aliran dilakukan berdasarkan pertimbangan akan kondisi tempat dan jaringan stasiun aliran. Hal yang harus dipertimbangkan berdasarkan kondisi tempat yaitu ketelitian pengukuran dan kestabilan penampang sungai dengan beberapa persyaratan yaitu dapat dipakai untuk mengukur aliran rendah sampai tinggi, tidak ada tumbuhan air, pada bagian sungai yang relatif lurus, dengan penampang sungai reguler dan stabil serta jauh dari cabang maupun muara sungai. Sedangkan pertimbangan berdasarkan jaringan stasiun aliran harus memperhatikan dari tujuan penelitian yang dilakukan.

Pengukuran debit dilakukan dengan metode Current Meter, kecepatan aliran diukur dengan current meter, dan dihitung berdasarkan jumlah putaran baling-baling per waktu putaran $(\mathrm{N})$ seperti ditunjukkan pada Gambar 1 dan dihitung menggunakan persamaan 1

$$
\begin{aligned}
& \mathrm{V}=\mathrm{aN}+\mathrm{b} \\
& \mathrm{V}=\text { kecepatan aliran (m/detik) }
\end{aligned}
$$


$\mathrm{a}, \mathrm{b}=$ konstanta alat

$\mathrm{N} \quad=$ jumlah putaran per waktu

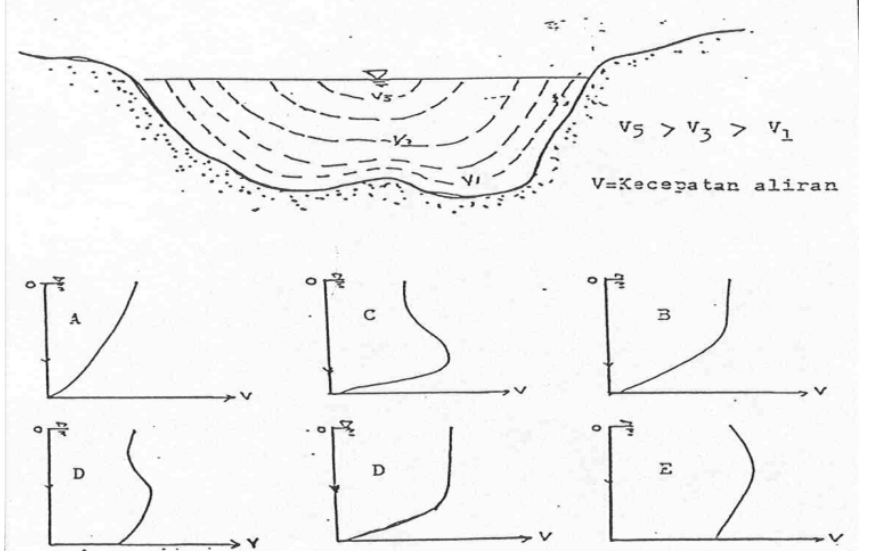

A : Teoritis

B : Dasar saluran kasar dan banyak tumbuhan

C : Gangguan permukaan

D : Aliran cepat, aliran turbulen pada dasar

E : Aliran lambat, dasar saluran halus

F : Dasar saluran kasar

Gambar 1. Distribusi kecepatan aliran [9].

\subsection{Pengukuran Paramater in situ}

Pengukuran ini meliputi parameter DO, pH, suhu, DHL, dan TDS.

\section{HASIL DAN PEMBAHASAN}

Hasil dari pengukuran in situ dan debit pada pengambilan sampel air Sungai Gajah Wong yang dilakukan pada Bulan Januari tahun 2020 dibandingkan dengan PerGub DIY No. 20 tahun 2008 klasifikasi mutu air kelas II disajikan pada Tabel 1. Berdasarkan hasil pengukuran insitu diperoleh hasil $\mathrm{pH}$ pada GW 1 ada di bawah baku mutu yang dipersyaratkan, yaitu sebesar 5,520 sedangkan untuk GW 2, GW 3, GW 4 DAN GW 5 berada dalam baku mutu yang dipersyaratkan. Nilai pH mengindikasikan apakah air tersebut netral, asam, atau basa. Air dengan $\mathrm{pH}$ dibawah 7 termasuk asam dan diatas 7 termasuk basa. Nilai pH menggambarkan seberapa besar tingkat keasaman atau kebasaan suatu perairan. Tingkat keasaman merupakan faktor yang penting dalam proses pengolahan air untuk perbaikan kualitas air. Kondisi perairan bersifat netral apabila nilai $\mathrm{pH}$ sama dengan 7 , kondisi perairan bersifat asam bila $\mathrm{pH}$ kurang dari 7, sedangkan $\mathrm{pH}$ lebih dari 7 kondisi perairan bersifat basa. Nilai baku mutu kualitas air sungai berkisar $6-8.5$.

TABEL I. Hasil pengukuran insitu dan debit

\begin{tabular}{|c|c|c|c|c|c|c|c|}
\hline \multirow[t]{2}{*}{ Parameter } & Satuan & Baku & GW 1 & GW 2 & GW 3 & GW 4 & GW 5 \\
\hline & & & $\begin{array}{c}\text { Jembatan } \\
\text { Santo } \\
\text { Thomas } \\
\text { LS } 07^{\circ} 47^{\prime} \\
19.6^{\prime \prime} \\
\text { BT } \\
110^{0} 23 \\
50.6^{\prime \prime}\end{array}$ & $\begin{array}{c}\text { Jembatan } \\
\text { Balirejo } \\
\text { LS } 07^{0} 47^{\prime} \\
43.2^{\prime} \\
\text { BT } \\
110^{0} 23 \\
46.8^{\prime}\end{array}$ & $\begin{array}{c}\text { Jembata } \\
\text { n } \\
\text { Gembira } \\
\text { loka } \\
\text { LS } \\
07^{0} 48^{\prime} \\
10.3^{\prime} \\
\text { BT } \\
110^{0} 23^{\prime} \\
51.4 \\
\end{array}$ & $\begin{array}{c}\text { Jembatan } \\
\text { Logathok } \\
\text { LS } 07^{0} 48^{\prime} \\
54.3^{\prime \prime} \\
\text { BT } \\
110^{0} 23 \\
51.4^{\prime \prime}\end{array}$ & $\begin{array}{c}\text { Jembatan } \\
\text { Tegalgen } \\
\text { du } \\
\text { LS } 07^{0} 49^{\prime} \\
34.1^{\prime} \\
\text { BT } \\
110^{0} 23 \\
20.1^{\prime \prime}\end{array}$ \\
\hline $\mathrm{pH}$ & & $6-8,5$ & $5,520^{*}$ & 6,590 & 6,630 & 6,720 & 6,750 \\
\hline Suhu & $\mathrm{C}$ & $\begin{array}{c}\text { suhu } \\
\text { udara } \\
30.67 \pm 3^{0}\end{array}$ & 29,64 & 28,64 & 29,65 & 29,65 & 28,64 \\
\hline TDS & $\mathrm{mg} / \mathrm{L}$ & 1000 & 193,5 & 199,4 & 213,0 & 217 & 219 \\
\hline DO & $\mathrm{mg} / \mathrm{L}$ & $5^{* *}$ & $4,76^{* *}$ & 5,15 & 6,11 & 5,42 & 5,18 \\
\hline DHL & $\begin{array}{c}\mu \mathrm{mhos} \\
/ \mathrm{cm}\end{array}$ & $\begin{array}{l}\text { Tidak } \\
\text { diper }\end{array}$ & 404,0 & 415,0 & 443,0 & 451 & 454,5 \\
\hline
\end{tabular}


syaratkan

\begin{tabular}{lllllll} 
Debit $\quad \mathrm{m}^{3} / \mathrm{s}$ & 0,783 & 0,452 & 0,784 & 1,118 & 0,624 \\
\hline
\end{tabular}

Sumber : data primer UPT Laboratorium Pengujian Kualitas Lingkungan DLH Kota Yk, 2020

$*=$ kurang/lebih dari baku mutu yang dipersyaratkan

**= kurang dari baku mutu minimal yang dipersyaratkan

Hasil pengukuran DO yang diperoleh menunjukkan hasil belum memenuhi standar baku mutu kelas II pada GW 1. Hal ini disebabkan oleh karena perubahan cuaca dan pergerakan massa air dan banyaknya lumut yang hidup di dasar mata air. Kecepatan difusi oksigen dari udara, tergantung dari beberapa faktor, seperti kekeruhan air, kedalaman dan pergerakan massa air .[7] Suhu air dipengaruhi oleh radiasi cahaya matahari, suhu udara, cuaca dan lokasi.

TABEL II. Kecepatan rata-rata

\begin{tabular}{cccc}
\hline Tipe & Kedalaman Air $(\mathrm{d})$ & Titik Pengamatan & $\begin{array}{c}\text { Kecepatan Rata-rata } \\
\text { vertikal }\end{array}$ \\
\hline Satu titik & $0,3-0,6 \mathrm{~m}$ & $0,6 \mathrm{~d}$ dari permukaan & $\mathrm{V}=\mathrm{V}$ \\
Dua titik & $0,6-3 \mathrm{~m}$ & $0,2 \mathrm{~d}$ dan $0,8 \mathrm{~d}$ & $\mathrm{~V}=1 / 2(\mathrm{~V} 2+\mathrm{V} 8)$ \\
Tiga titik & $3-6 \mathrm{~m}$ & $0,2 \mathrm{~d} ; 0,6 \mathrm{~d} ; 0,8 \mathrm{~d}$ & $\mathrm{~V}=1 / 4(\mathrm{~V} 2+2 \mathrm{~V} 6+$ \\
$\mathrm{V} 8)$ & & $\begin{array}{c}\mathrm{V}=1 / 10(\mathrm{Vs}+3 \mathrm{~V} 2+ \\
2 \mathrm{~V} 6+3 \mathrm{~V} 8+\mathrm{Vb})\end{array}$ \\
\hline
\end{tabular}

Sumber : [6],[8].

Dimana :

$\mathrm{d}=$ Kedalaman pengukuran

$\mathrm{s}=$ Permukaan sungai

$\mathrm{b}=$ Dasar sungai

$\mathrm{v}=$ Kecepatan aliran $(\mathrm{m} /$ detik $)$

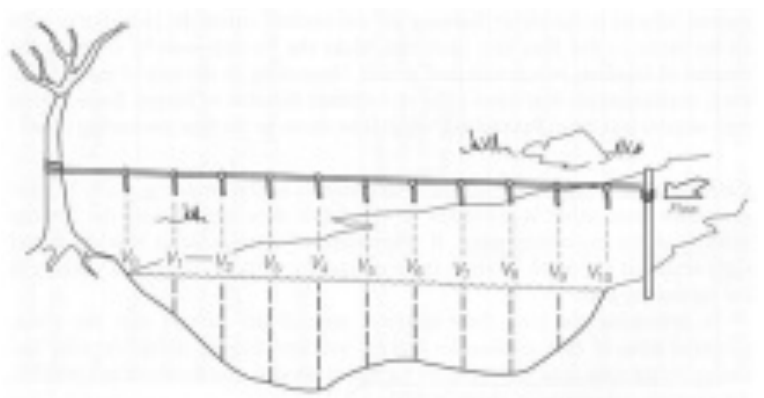

Gambar 2. Pengukuran kedalaman [9].

Pada suhu air yang hangat, kapasitas oksigen terlarutnya berkurang. Hal ini disebabkan oleh karena cuaca yang terjadi di lokasi penelitian ketika melakukan pengukuran suhu adalah berawan. Pada hasil pengukuran di lapangan, diperoleh bahwa di semua lokasi, diperoleh suhu yang masih memenuhi baku mutu yang dipersyaratkan. Pengukuran TDS dilakukan untuk mengukur banyaknya zat padat total pada sampel dalam satuan $\mathrm{mg} / \mathrm{L}$. Padatan terlarut alami berasal dari pelapukan batuan dan tanah. Sedangkan pengukuran DHL dilakukan untuk mengetahui daya hantar listrik dari suatu sampel dengan satuan $\mu \mathrm{mhos} / \mathrm{cm}$. Pada hasil pengukuran di lapangan, diperoleh bahwa di semua lokasi, diperoleh TDS dan DHL yang masih memenuhi baku mutu yang dipersyaratkan. Pengukuran debit dilakukan dengan metode current meter dengan hasil yang diperoleh seperti ditunjukkan pada Tabel II dengan teknik sampling seperti pada Gambar 2. Adapun perhitungan nilai debit pengukuran ditunjukkan mengikuti Gambar 3 dan 4. 


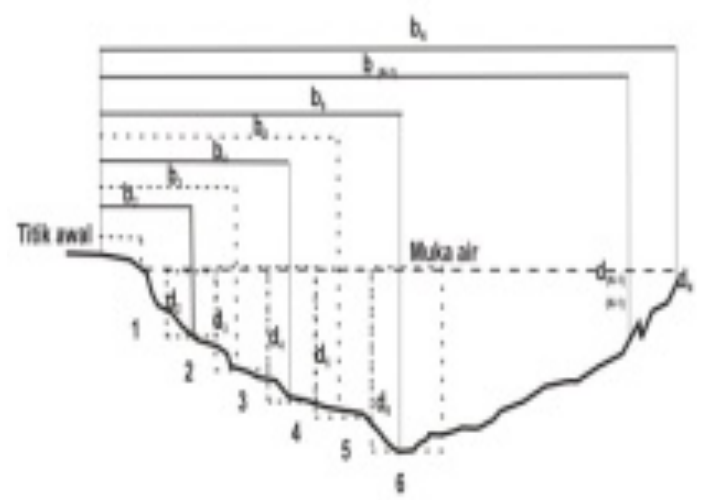

$$
\begin{aligned}
& \mathrm{q}_{\mathrm{x}}=\overline{\mathrm{V}}_{x} \mathrm{~d}_{\mathrm{x}}\left[\frac{\mathrm{b}(\mathrm{x}+1)-\mathrm{b}(\mathrm{x}-1)}{2}\right] \\
& \mathrm{Q}=\sum_{\mathrm{i}=1}^{\mathrm{n}+1} \mathrm{q}_{\mathrm{i}} \\
& \mathrm{qx}: \text { debit perbagian pengukuran } \\
& \mathrm{Vx}: \text { kecepatan alir di titik } \mathrm{x} \\
& \mathrm{dx}: \text { kedalaman sungai di titik } \mathrm{x} \\
& \mathrm{b}: \text { lebar sungai di titik } \mathrm{x} \\
& \mathrm{Q}: \text { debit sungai }
\end{aligned}
$$

Gambar 3. Metode penampang tengah (Mid Section Method) [9]

Pengukuran debit dilakukan dengan dengan membagi penampang basah sungai setiap satu (1) meter. Metode pengukuran tengah seperti pada (Mid Section Method), dengan menghitung nilai debit dari jumlah kecepatan yang terbaca pada current meter dikalikan kedalaman sungai dikalikan lebar sungai. Nilai total debit merupakan jumlah dari debit air disepanjang titik penampang basah .

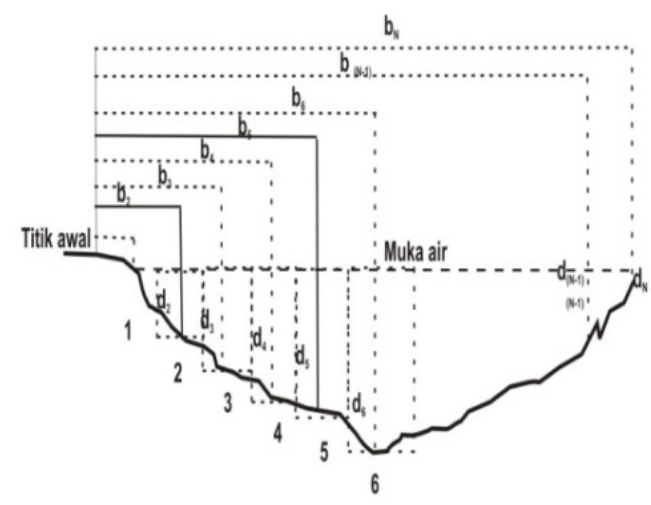

$$
\begin{gathered}
\mathrm{q}_{\mathrm{x}}=\frac{\left(\overline{\mathrm{V}}_{x}+\mathrm{V}_{\mathrm{x}-1}\right)}{2} \cdot \frac{\left(\mathrm{d}_{x}+\mathrm{d}_{\mathrm{x}-1}\right)}{2} \cdot\left(\mathrm{b}_{x}-\mathrm{b}_{\mathrm{x}-1}\right) \\
\mathrm{Q}=\sum_{\mathrm{i}=1}^{\mathrm{n}+1} \mathrm{q}_{\mathrm{i}}
\end{gathered}
$$

qx : debit perbagian pengukuran

Vx: kecepatan alir di titik $\mathrm{x}$

$\mathrm{dx}$ : kedalaman sungai di titik $\mathrm{x}$

b : lebar sungai di titik $\mathrm{x}$

Q : debit sungai

Gambar 4. Metode penampang rata-rata (Mean Section Method) [9].

Metode penampang rata-rata (Mean Section Method), merupakan metode yang menghitung nilai debit dengan menghitung rata- rata kecepatan dikalikan kedalaman rata-rata dikalikan dengan lebar sungai pada suatu titik. Debit total merupakan jumlah debit pada tiap- tiap titik.

Pengawetan dan penyimpanan sampel yang dilakukan pada pengambilan sampel air Sungai Gajah Wong ditunjukkan pada Tabel III sesuai dengan parameter yang akan diuji di laboratorium. Selama perjalanan, sampel dari lokasi pengambilan sampai ke laboratorium, harus ditempatkan ke dalam wadah khusus (ice box) dengan diberi ice gel untuk menjaga suhu penyimpanan sampel. Sampel harus tertutup rapat, supaya tidak tumpah dan tidak terjadi kontaminasi silang. 
TABEL III. Pengawetan dan Penyimpanan Sampel

\begin{tabular}{|c|c|c|c|c|c|c|}
\hline No & Parameter & $\begin{array}{c}\text { Wadah } \\
\text { penyimpanan }\end{array}$ & $\begin{array}{l}\mathrm{V} \min . \\
(\mathrm{mL})\end{array}$ & Pengawetan & $\begin{array}{c}\text { Lama } \\
\text { penyimpanan }\end{array}$ & $\begin{array}{c}\text { Lama } \\
\text { penyimpanan } \\
\text { menurut EPA }\end{array}$ \\
\hline 1 & COD & $\mathrm{P}, \mathrm{G}$ & 100 & $\begin{array}{l}\text { Analisa } \\
\text { secepatnya } \\
\text { atau } \\
\text { ditambah } \\
\mathrm{H}_{2} \mathrm{SO}_{4} \text { sampai } \\
\mathrm{pH}<2 \text {, } \\
\text { didinginkan }\end{array}$ & 7 hari & 28 hari \\
\hline 2 & Fluorida & $\mathrm{P}$ & 300 & $\begin{array}{l}\text { Tanpa } \\
\text { diawetkan }\end{array}$ & 28 hari & 28 hari \\
\hline 3 & $\begin{array}{l}\text { Logam } \\
\text { (secara } \\
\text { umum) }\end{array}$ & $P(A), G(A)$ & - & $\begin{array}{l}\text { Untuk logam } \\
\text { logam } \\
\text { terlarut } \\
\text { sampel segera } \\
\text { disaring, } \\
\text { ditambah } \\
\mathrm{HNO}_{3} \text { sampai } \\
\mathrm{pH}<2 \\
\text { didinginkan }\end{array}$ & 6 bulan & 6 bulan \\
\hline 4 & $\begin{array}{l}\text { Amonia- } \\
\text { Nitrogen }\end{array}$ & $\mathrm{P}, \mathrm{G}$ & 500 & $\begin{array}{l}\text { Analisa } \\
\text { secepatnya atau } \\
\text { ditambah } \\
\mathrm{H}_{2} \mathrm{SO}_{4} \text { sampai } \\
\text { pH }<2 \text {, } \\
\text { didinginkan }\end{array}$ & 7 hari & 28 hari \\
\hline 5 & Nitrat + Nitrit & $\mathrm{P}, \mathrm{G}$ & 200 & $\begin{array}{l}\text { ditambah } \\
\mathrm{H}_{2} \mathrm{SO}_{4} \text { sampai } \\
\mathrm{pH}<2 \text {, } \\
\text { didinginkan }\end{array}$ & - & 28 hari \\
\hline \multirow[t]{2}{*}{6} & $\begin{array}{l}\text { Oksigen } \\
\text { Terlarut }\end{array}$ & G Botol BOD & 300 & & & \\
\hline & $\begin{array}{l}\text { Dengan } \\
\text { Elektroda }\end{array}$ & & & $\begin{array}{l}\text { Langsung } \\
\text { dianalisa }\end{array}$ & - & $0,25 \mathrm{jam}$ \\
\hline 7 & Fosfat & $\mathrm{G}(\mathrm{A})$ & 100 & $\begin{array}{l}\text { Untuk fosfat } \\
\text { terlarut segera } \\
\text { disaring } \\
\text { didinginkan }\end{array}$ & 48 jam & \\
\hline
\end{tabular}

Sumber : [9] 
Untuk parameter COD dan Amonia-Nitrogen, jika tidak segera diuji maka sampel harus ditambah dengan $\mathrm{H}_{2} \mathrm{SO}_{4}$ hingga $\mathrm{pH}$ kurang dari 2 dengan masa simpan hingga 7 hari menurut SNI dan 28 hari menurut EPA. Parameter DO dengan menggunakan metode titrasi harus ditambahkan larutan alkali serta larutan $\mathrm{MnSO}_{4} \cdot \mathrm{H}_{2} \mathrm{O}$ ketika pengambilan sampel di lapangan dan segera dilakukan pengujian ketika sampel tiba di laboratorium. Untuk parameter nitrat dan nitrit penyimpanan menurut EPA mencapai 28 hari dengan kondisi didinginkan setelah penambahan $\mathrm{H}_{2} \mathrm{SO}_{4}$ hingga $\mathrm{pH}$ kurang dari 2 . Parameter Fosfat terlarut, sampel harus segera disaring dan didinginkan, masa simpan untuk fosfat adalah 48 jam, sedangkan untuk fluoride meskipun tanpa pengawet dan perlakuan khusus bisa mencapai masa simpan selama 28 hari. Untuk Parameter-parameter logam terlarut seperti $\mathrm{Cu}, \mathrm{Zn}$, $\mathrm{Fe}, \mathrm{Mn}, \mathrm{Cd}$ dan $\mathrm{Pb}$, sampel harus disaring dan ditambah $\mathrm{HNO}_{3}$ hingga $\mathrm{pH}$ kurang dari 2 kemudian didinginkan, setelah pengawetan mampu mempunyai masa simpan yang mencapai 6 bulan.

\section{KESIMPULAN}

Berdasarkan hasil penelitian yang dilakukan, maka pengambilan sampel Sungai Gajah Wong, yang dilakukan pada Bulan Januari tahun 2020 bertujuan sebagai pemantauan kualitas air sungai di Kota Yogyakarta. Hasil pengukuran untuk paremeter insitu $\mathrm{pH}$ dan DO pada GW 1 ada di bawah baku mutu yang dipersyaratkan yaitu 5.520 untuk $\mathrm{pH}$ dan 4.76 untuk hasil DO. Sedangkan parameter suhu, DHL dan TDS masih memenuhi baku mutu yang dipersyaratkan. Debit diukur dengan metode current meter dan dihitung dengan metode penampang tengah dan diperoleh debit aliran Sungai Gajah Wong pada saat pengambilan sampel adalah $0.783 \mathrm{~m}^{3} / \mathrm{s}, 0.452 \mathrm{~m}^{3} / \mathrm{s}, 0,784 \mathrm{~m}^{3} / \mathrm{s}, 1,118 \mathrm{~m}^{3} / \mathrm{s}$ dan $0,624 \mathrm{~m}^{3} / \mathrm{s}$.

\section{Ucapan Terima Kasih}

Terima kasih kami ucapkan kepada seluruh personil UPT Laboratorium Pengujian Kualitas Lingkungan DLH Kota Yogyakarta.

\section{Daftar Pustaka}

[1] R. Risyanto and M. Widyastuti, "Pengaruh Perilaku Penduduk Dalam Membuang Limbah Terhadap Kualitas Air Sungai Gajahwong (The Influence of People Behaviour in Disposing Waste to the Gajahwong Water Quality)," J. Mns. dan Lingkung., vol. 11, no. 2, pp. 73-85, 2004, doi: 10.22146/JML.18621.

[2] E. Nuraini and Sunardi, "Kualitas Lingkungan Sungai Code Dan Gajahwong Ditinjau Dari Kadar Cu Dan Cr Dalam Cuplikan Sedimen," Pros. Pertem. Ilm. XXIV HFI Jateng dan DIY, no. April, pp. 328 $338,2010$.

[3] E. Winata and E. Hartantyo, "Kualtias Air Tanah di Sepanjang Kali Gajah Wong Ditinjau dari Pola Sebaran Escherichia Coli (Studi Kasus Kecamatan Umbulharjo) (Halaman 8 s.d. 11)," J. Fis. Indones., vol. 17 , no. 50, pp. 8-11, 2014, doi: 10.22146/jfi.24415.

[4] F. D. O. Riswanto, M. Hariono, G. N. Susanto, I. Y. K. Budiasmoro, and E. P. Istyastono, "Kualitas Air Sungai Gajah Wong Ditinjau Dari Penghambatan Enzim Asetilkolinesterase (Water Quality Assessment of Gajah Wong River Based on Inhibition of Acetylcholinesterase Activity)," J. Mns. dan Lingkung., vol. 24, no. 2, p. 89, 2018, doi: 10.22146/jml.23046.

[5] E. Widiastuti and T. Campus, "The impact of the local dairy cattle farm toward the river water quality in Gunungpati Subdistrict Central Java," Int. J. Sci. Eng., vol. 8, no. 1, pp. 15-21, 2015, doi: 10.12777/ijse.8.1.15-21.

[6] A. Norhadi, A. Marzuki, L. Wicaksono, and R. Addetya Yacob, "Studi Debit Aliran pada Sungai Antasan Kelurahan Sungai Andai Banjarmasin Utara," J. Poros Tek., vol. 7, no. 1, pp. 1-53, 2015, doi: 10.1016/j.apnu.2015.08.018.

[7] Salmin, "Oksigen terlarut (DO) Dan kebutuhan oksigen biologi (BOD) sebagai salah satu indikator untuk menentukan kualitas perairan," Oseana, vol. 30, no. 3, pp. 21-26, 2005.

[8] Triatmodjo, Bambang, 2008, "Hidrologi Terapan”, Beta Offset, Yogyakarta 
[9] SNI No. 6989.57:2008, "Metoda Pengambilan Contoh Air Permukaan"

\section{(c) (i) (2)}

Jurnal IJCA is licensed under aÂ Creative Commons Attribution ShareAlike 4.0 